\title{
Identification of the Success Factors of the Green Bond Market for Sustainable Development in the COVID-19 Era
}

\author{
Ehsan Rasoulinezhad ${ }^{1}$ (D) ${ }^{\mathrm{a}}$ \\ 1 University of Tehran, Iran \\ Keywords: interactive management approach, sustainable development, green bond market, JEL G15 G38 \\ https://doi.org/10.46557/001c.29979
}

\section{Energy RESEARCH LETTERS}

Vol. 3, Issue 3, 2022

\begin{abstract}
This paper attempts to identify the most important factors for the success of the green bond market during the COVID-19 pandemic. Using an interactive management approach, we find that the legal framework for green bond operation and the interest rate of green bond are the major factors in determining the success of the green bond market during the COVID-19 pandemic.
\end{abstract}

\section{Introduction}

It is widely discussed in the literature that the negative consequences of the COVID-19 pandemic have shrunk the volume of capital in financing projects (Amir \& Zubair Khan, 2021; Donthu \& Gustafsson, 2020), especially those that are related to green energy. Eroglu (2020) has declared that, due to the outbreak of COVID-19, the increases in wind and solar energy capacities for 2020 are estimated to have been reduced by $4.9 \mathrm{GW}$ and $28 \%$, respectively. It is a commonly accepted that countries need private participation in green projects to cover for lack of state capital, as well as for the improvement of capital mobility across national borders. Mazzucato \& Semieniuk (2018) and Polzin et al. (2019) argue that the private sector is a more reliable and agile investor than the government in environmental projects due to its social responsibilities and rational performance in economic activities.

Regarding the above-mentioned problem, green bonds (GBs) are a fresh and appropriate asset-linked fixed-income instrument that can help countries raise capital for green projects, to improve environmental quality and reduce the threat of climate change (Anh et al., 2021; Aung et al., 2017; Esfahani \& Rasoulinezhad, 2015). Accordingly, this instrument, as a reliable way to boost green projects and to reach the targets of the Sustainable Development Goals, was first introduced in 2008 by the World Bank in the Strategic Framework on Development and Climate Change. Trang (2015) has expressed that the GB market can provide adequate financing projects related to green energy resources.

Due to the immense importance of GB in boosting green project financing, the objective of this paper is to determine and evaluate critical success factors of the GB market during the current pandemic. Despite the unique and fruitful advantages of GBs, their success is not permanent and there is much evidence on the failure of the GB market in various countries (Ferrer et al., 2021; McInerney \& Bunn, 2019). Although a group of researchers (e.g., Trang, 2015; Tu et al., 2020; Wang et al., 2020; Naeem et al., 2021; Taghizadeh-Hesary et al., 2021) has addressed the GB market, to the best of our knowledge no study has yet identified the critical success factors of the market during the current pandemic. Therefore, this paper attempts to fill this literature gap by applying an interactive management approach.

The major findings of this study reveal the importance of the legal framework of the GB market, which ensures its efficient operation, and the interest rates of GBs that attract private investor capital to green projects during COVID-19 conditions.

This remainder of the paper is organized as follows. The literature is briefly reviewed in Section II. The methodology and findings are reported in Section III. The last section, Section IV, provides conclusions and recommends practical policies.

\section{Literature review}

Reboredo (2018) notes that the diversification benefits of GBs for investors and issuers should be considered a major factor contributing to the development of the GB market. In a recent study, Tu et al. (2020) investigate the ways of developing the GB market in Vietnam. They find that fiscal and monetary policies, interest rates, and market regulations are the most important factors in the development of Vietnam's GB market. Wang et al. (2020) focus on China as the pioneer of GB issuance worldwide. Their major finding is that the GB price premium plays a vital role in attracting private investors. Pham \& Huynh (2020) believe that market transparency as well as the existence of adequate in- 
formation for investors are the two most effective elements in GB market development. Yi et al. (2021) study the effect of the current pandemic on China's GB market and find that information asymmetry and the financial capacity of issuers are the two major factors in combating the negative consequences of the COVID-19 pandemic in the GB market. Jakubik \& Uguz (2021) emphasize the role of GB regulations in the activities and efficiency of insurers. Chen \& Zhao (2021) and Zhou et al. (2021) examine the role of GBs in expanding the Chinese financial market and demonstrate the positive contribution of GBs to financial market development. Ferrer et al. (2021) believe that the GB tool is a golden strategy for the decarbonization of energy and to reach better levels of environmental protection.

This brief literature review shows that the study of critical success factors of GBs has been neglected. Our paper attempts to fill this literature gap.

\section{Methodology and results \\ A. Methodology}

To identify critical success factors for the GB market's development during the COVID-19 pandemic, we used an interactive management approach. This approach, first proposed by Warfield \& Cardenas (1994), is a popular method for solving complex economic problems. As Gholami et al. (2016) declare, this method can help transform vague and poorly articulated problems into clear and well-defined solutions. Generally, the interactive management approach has various steps, in which we first need to identify the main players (issuers and investors) in the GB market. In the first stage of this study, the identification was carried out through the questions asked by Mason \& Mitroff (1981), which were answered by a panel of 10 experts. The second stage comprises the generation of critical success factors based on the experts' perceptions and experiences. Finally, the critical success factors thus obtained are then clarified through a model/diagraph of their interrelations.

\section{B. Results}

In this study, we asked 10 experts in the field of green financing to identify the critical success factors of the GB market. Table 1 presents the nine critical success factors (i.e., those chosen from the 30 selected factors and which over $50 \%$ of experts identified as critical success factors in the development of the GB market during the COVID-19 pandemic).

Next, we construct a structural self-interaction matrix by conducting pairwise comparisons of each expert's critical success factors $i$ and $j$, based on four symbols $-v$ (denoting that critical success factor $i$ will help achieve critical success factor $j$ ), $A$ (denoting that critical success factor $j$ will help achieve critical success factor $i$ ), $X$ (denoting that critical success factors $i$ and $j$ will help achieve each other), and $O$ (denoting no specific relation between the critical success factors $i$ and $j$ )-to reveal the interrelations between the critical success factors identified in Table 1. Next, a reachability matrix was generated from the structural self-interaction matrix, and, finally, a diagraph model was developed based on the transitive links among our nine critical success factors. As shown in Figure 1, the legal framework of the GB market and official interest rates of GBs were found at the first level, meaning that these two factors are at the top of the hierarchy of success factors. Moreover, these were found to be significant success factors for the development of the GB market during the COVID-19 pandemic.

It should be noted that the inflation rate, monetary policy, and fiscal policy are at the second level of the success hierarchy, while institutional infrastructure and international cooperation in GBs are at the third level. The final level includes official exchange rates and political stability, which are not as important as the other factors mentioned earlier for GB market success during the current pandemic. Note, also, that the exchange rate and political stability being at the last level of the model does not mean that they are inappropriate-only that the experts gave them less priority compared to the other factors examined.

Figure 1 illustrates the interpretive structural model for these four levels of importance.

In Figure 1, the direction of the arrow represents the relation between the critical success factors at different levels. For instance, the relation between the legal framework for GBs and their interest rate is found to be unidirectional. Furthermore, it can be seen that monetary policy affects the inflation rate, the official exchange rate, and the interest rate of GBs. International cooperation in GBs at the third level can also affect the institutional infrastructure and improve the legal framework for the GB market.

\section{Conclusions and policy recommendations}

In this study, we empirically investigated the critical success factors for the GB market's successful operation during the COVID-19 pandemic. With this aim, we employed semi-structured interviews with 10 experts in the field of green financing. By conducting content analysis, we thus determined nine critical success factors. These critical success factors were then put into an interactive structural model, to explore their interactions. The results highlight the importance of the legal framework of the GB market, ensuring efficient market operation, as well as the interest rate of GBs in attracting private investor capital to green projects under COVID-19 conditions. In addition to these two important factors, fiscal policy, monetary policy, and inflation rates are found to be three significant factors in the success of the GB market, while international cooperation in GBs and institutional infrastructure also play a role in the successful implementation of GBs in an economy during the COVID-19 pandemic.

The practical implications of this paper are in line with the various Sustainable Development Goals targets of the United Nations, such as goal 7 (affordable and clean energy), goal 13 (climate action), and goal 15 (life on land). Moreover, to promote the GB market in different countries, both partnership and coordination between private (domestic and foreign) and public sectors are recommended.

Furthermore, legal documentation at the government decree level regarding GB programs as a basis for their implementation is vital for the GB market's successful imple- 
Table 1. Critical success factors for green bond market development

\begin{tabular}{lc}
\hline Critical success factor & Percentage of identification by experts \\
\hline Official interest rate of GB & $95 \%$ \\
Legal framework of GB & $82 \%$ \\
Institutional infrastructure & $80 \%$ \\
International cooperation in GB & $76 \%$ \\
Monetary Policy & $70 \%$ \\
Fiscal Policy & $69 \%$ \\
Inflation rate & $60 \%$ \\
Political stability & $53 \%$ \\
Official exchange rate & $51 \%$ \\
\hline
\end{tabular}

This table shows the major factors influencing the success of the green bond market. Source: Authors' calculation based on experts' opinions.

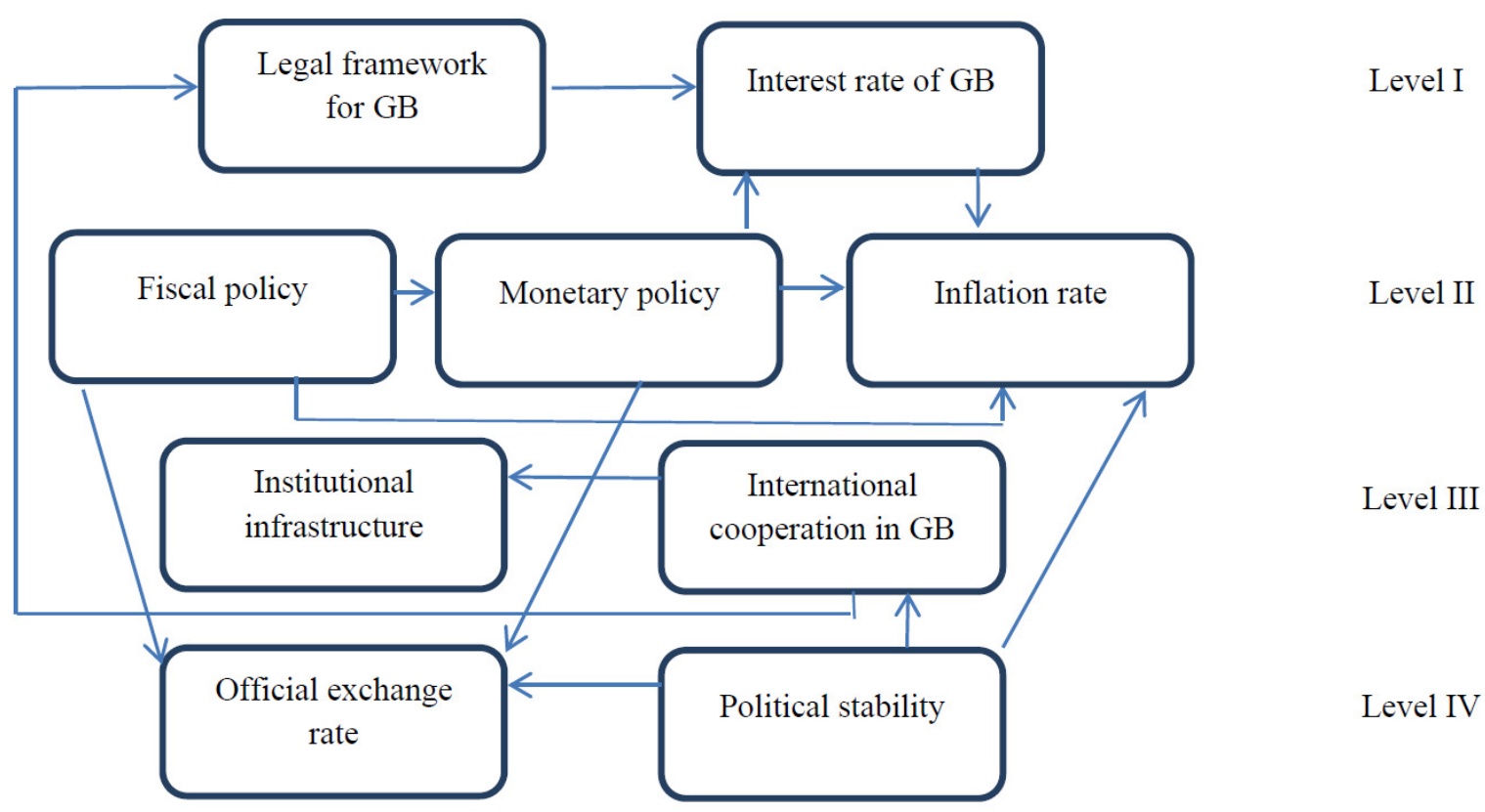

Figure 1. ISM model

This figure displays the ISM model. Source: Authors' compilation.

mentation during the COVID-19 pandemic. Notably, this legal framework can ensure information transparency for a competitive GB market where private investors can easily determine the different legal aspects of the GB market, as well as their returns of investment.

In addition, in developing countries, reforms and revisions of fiscal and monetary policies related to the GB market are highly recommended. To this end, a roadmap for policy reforms can help these countries find a clear path to the development of a GB market during the COVID-19 pandemic and beyond. In such cases, international cooperation (e.g., the Network of Central Banks and Supervisors for Greening the Financial System, launched in 2017, and the International Platform on Sustainable Finance, launched in 2019) is a useful and synergistic strategy that can be used to enhance GB market operations. 


\section{References}

Amir, M., \& Zubair Khan, S. (2021). Assessment of renewable energy: Status, challenges, COVID-19 impacts, opportunities, and sustainable energy solutions in Africa. Energy and Built Environment. In press. https://doi.org/10.1016/j.enbenv.2021.03.002

Anh, T. C., Rasoulinezhad, E., Chi, T. N., Ba, H. L. H., \& Hoang Than, H. (2021). Modeling energy securityexchange rate linkage: Evidence of GMM approach. The Singapore Economic Review, 66(02), 529-544. http s://doi.org/10.1142/s0217590819430021

Aung, T. S., Saboori, B., \& Rasoulinezhad, E. (2017). Economic growth and environmental pollution in Myanmar: An analysis of environmental Kuznets curve. Environmental Science and Pollution Research, 24(25), 20487-20501. https://doi.org/10.1007/s1135 6-017-9567-3

Chen, Y., \& Zhao, Z. J. (2021). The rise of green bonds for sustainable finance: Global standards and issues with the expanding Chinese market. Current Opinion in Environmental Sustainability, 52, 54-57. https://do i.org/10.1016/i.cosust.2021.06.013

Donthu, N., \& Gustafsson, A. (2020). Effects of COVID-19 on business and research. Journal of Business Research, 117, 284-289. https://doi.org/10.1 016/j.jbusres.2020.06.008

Eroglu, H. (2020). Effects of Covid-19 outbreak on environment and renewable energy sector. Environment, Development and Sustainability, 23, 4782-4790.

Esfahani, M. N., \& Rasoulinezhad, E. (2015). Will be there new $\mathrm{CO} 2$ emitters in the future? Evidence of long-run panel co-integration for N-11 countries. International Journal of Energy Economics and Policy, 6(3), 463-470.

Ferrer, R., Shahzad, S. J. H., \& Soriano, P. (2021). Are green bonds a different asset class? Evidence from time-frequency connectedness analysis. Journal of Cleaner Production, 292, 125988. https://doi.org/10.10 16/j.jclepro.2021.125988

Gholami, H., Rezaei, G., Saman, M. Z. M., Sharif, S., \& Zakuan, N. (2016). State-of-the-art Green HRM System: Sustainability in the sports center in Malaysia using a multi-methods approach and opportunities for future research. Journal of Cleaner Production, 124, 142-163. https://doi.org/10.1016/j.jcl epro.2016.02.105

Jakubik, P., \& Uguz, S. (2021). Impact of green bond policies on insurers: Evidence from the European equity market. Journal of Economics and Finance, 45(2), 381-393. https://doi.org/10.1007/s12197-020-0 9534-4

Mason, R. O., \& Mitroff, I. I. (1981). Challenging strategic planning assumptions. John Wiley.

Mazzucato, M., \& Semieniuk, G. (2018). Financing renewable energy: Who is financing what and why it matters. Technological Forecasting and Social Change, 127, 8-22. https://doi.org/10.1016/i.techfore.2017.0 $\underline{5.021}$
McInerney, C., \& Bunn, D. W. (2019). Expansion of the investor base for the energy transition. Energy Policy, 129, 1240-1244. https://doi.org/10.1016/i.enpol.201 9.03.035

Naeem, M. A., Nguyen, T. T. H., Nepal, R., Ngo, Q.-T., \& Taghizadeh-Hesary, F. (2021). Asymmetric relationship between green bonds and commodities: Evidence from extreme quantile approach. Finance Research Letters, 43, 101983. https://doi.org/10.1016/ j.frl.2021.101983

Pham, L., \& Huynh, T. (2020). How does investor attention influence the green bond market? Finance Research Letters, 35, 101533. https://doi.org/10.1016/ j.frl.2020.101533

Polzin, F., Egli, F., Steffen, B., \& Schmidt, T. S. (2019). How do policies mobilize private finance for renewable energy?-A systematic review with an investor perspective. Applied Energy, 236, 1249-1268. https://doi.org/10.1016/j.apenergy.2018.11.098

Reboredo, J. C. (2018). Green bond and financial markets: Co-movement, diversification and price spillover effects. Energy Economics, 74, 38-50. http s://doi.org/10.1016/i.eneco.2018.05.030

Taghizadeh-Hesary, F., Yoshino, N., \& Phoumin, H. (2021). Analyzing the characteristics of green bond markets to facilitate green finance in the postCOVID-19 World. Sustainability, 13(10), 5719. http s://doi.org/10.3390/su13105719

Trang, N. M. (2015). Green bonds and its prospects in Vietnam. Vietnam Journal of Theoretical Activities, 5, 14-23.

Tu, C. A., Rasoulinezhad, E., \& Sarker, T. (2020). Investigating solutions for the development of a green bond market: Evidence from analytic hierarchy process. Finance Research Letters, 34, 101457. http s://doi.org/10.1016/j.frl.2020.101457

Wang, J., Chen, X., Li, X., Yu, J., \& Zhong, R. (2020). The market reaction to green bond issuance: Evidence from China. Pacific-Basin Finance Journal, 60, 101294. https://doi.org/10.1016/j.pacfin.2020.101 $\underline{294}$

Warfield, J. N., \& Cardenas, A. R. (1994). A handbook of interactive management. Iowa State University Press.

Yi, X., Bai, C., Lyu, S., \& Dai, L. (2021). The impacts of the COVID-19 pandemic on China's green bond market. Finance Research Letters, 42, 101948. http s://doi.org/10.1016/i.frl.2021.101948

Zhou, X., Zhang, R., \& Polochova, V. (2021). The dependence of Chinese green and conventional bond markets under extreme and normal market conditions. Environmental Science and Pollution Research, 28, 11356-11021. https://doi.org/10.1007/s 11356-021-14050-x 